\title{
A Small Bite on the Eyelid
}

\section{Göz Kapağında Küçük Bir Isırık}

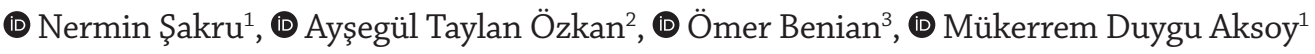

${ }^{1}$ Trakya University Faculty of Medicine, Department of Medical Microbiology, Edirne, Turkey

${ }^{2}$ Hitit University Faculty of Medicine, Department of Medical Microbiology, Çorum, Turkey

${ }^{3}$ Trakya University Faculty of Medicine, Department of Ophthalmology, Edirne, Turkey

Cite this article as: Şakru N, Özkan AT, Benian Ö, Aksoy D. A Small Bite on the Eyelid. Türkiye Parazitol Derg 2019; 43(1):53

\section{A SMALL BITE ON THE EYELID}

A 4-year-old boy presented with a 3 days history of a dark colored lesion on his right upper eyelid. The child's mother noticed the lesion between his lashes. He had very little pruritus and redness on his upper eyelid. When the small lesion was gradually getting larger, they admitted to the ophthalmology department of Trakya University Hospital. Close examination revealed that foreign body attached to the eyelid margin. As a result of inspection, it was found to be a tick (Figure 1). Tick was removed according to procedure without leaving any residual parts. Then, it was sent to Parasitology laboratory for identification. It was found to be a motile, female Hyalomma tick with microscopic examination. Patient was sent home and followed for ocular and tick-borne diseases during 10 days. There was no problem related to patients' health associated with the tick.

Hyalomma is a genus of hard-bodied ticks, common in Asia, Europe and North Africa. It is well-known

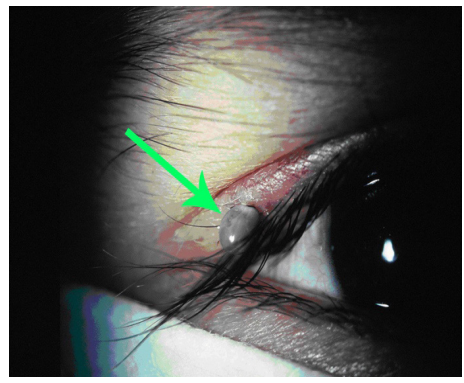

Figure 1. A feeding tick (arrow) on his right upper eyelid

vectors of viruses and parasites of human and animals. One of the most important diseases transmitted by Hyalomma marginatum is Crimean Congo hemorrhagic fever. Disease affects more than 30 countries including Turkey and most of the cases have been reported in the middle Black Sea and northern inner Anatolia regions in Turkey. 